\title{
Hypoxic pulmonary vasoconstriction in COPD-associated pulmonary hypertension: been there, done that?
}

\author{
Harm Jan Bogaard \\ Affiliation: Pulmonary Medicine, VU University Medical Center, Amsterdam, The Netherlands.
}

Correspondence: Harm Jan Bogaard, VU University Medical Center, Pulmonary Medicine, de Boelelaan 1117 Amsterdam 1007MB, The Netherlands. E-mail: hj.bogaarddvumc.nl

@ERSpublications

Hypoxic pulmonary vasoconstriction, mediated by p22phox, is a double-edged sword in COPD http://ow.ly/QiaC30cMgPZ

Cite this article as: Bogaard HJ. Hypoxic pulmonary vasoconstriction in COPD-associated pulmonary hypertension: been there, done that? Eur Respir J 2017; 50: 1701191 [https://doi.org/10.1183/ 13993003.01191-2017].

To many of us involved in teaching pulmonary physiology and gas exchange to medical students, hypoxic pulmonary vasoconstriction (HPV) is a favourite topic. The unique property of small pulmonary arteries to constrict in response to a reduced alveolar oxygen tension allows us to cover not only the complexities of ventilation perfusion matching, but also to dive into the more exciting "physiological classics", such as the fetal circulation and high altitude adaptation. Ever since von Euler and Liljestrand described their observations on pulmonary arterial blood pressure in the hypoxic cat [1], scientists have been dedicated to better understand the pulmonary vascular response to hypoxia. It is generally accepted that the endothelial cell plays a central role in hypoxic sensing [2], and that hypoxic sensing involves changing levels of reactive oxygen species (ROS) - although the direction of this change (up or down) continues to be debated [3,4]. Mitochondria and NADPH oxidase (Nox) are considered as the major sources of ROS production in the pulmonary vasculature [5].

While recognising the benefit of HPV to maintain arterial oxygen tension in many pathological conditions associated with impaired alveolar ventilation (e.g. pneumonia and pulmonary oedema), HPV was long held responsible for the pathological alterations in lung vessels occurring in chronic lung diseases, particularly chronic obstructive pulmonary disease (COPD). Accordingly, for many years HPV was the usual suspect when trying to explain the development of pulmonary hypertension in COPD. More recently, the role of hypoxia in the development of pulmonary hypertension in COPD was questioned. The relationship between arterial oxygen tension and pulmonary artery pressure is very weak [6] and long-term oxygen therapy does not fully reverse pulmonary hypertension or vascular remodelling in severe COPD [7]. PEINADo et al. [8] observed endothelial dysfunction and vascular remodelling in lungs of normoxaemic patients with mild COPD and even in smokers with normal pulmonary function. The predominant type of pulmonary vascular remodelling in COPD is enlargement of the intimal layer in muscular arteries [9], which is very much unlike the type of remodelling seen in healthy highlanders and patients with chronic mountain sickness [10]. Whether this prominent feature of pulmonary vascular remodelling in COPD has any relationship to the development of pulmonary hypertension remains to be proven, however. We recently observed very similar vascular intimal changes in the lungs of non-smoking normal subjects without COPD and without pulmonary hypertension [11].

Received: June 162017 | Accepted: June 162017

Conflict of interest: None declared.

Copyright OERS 2017 
At a time when pulmonary hypertension in COPD is rather attributed to endothelial dysfunction, apoptosis and perivascular inflammation, whether or not directly under the influence of cigarette smoke [12], the issue of HPV in COPD is revisited in this edition of the European Respiratory Journal. In their very carefully conducted study, NAGARAj et al. [13] show the crucial role of p22phox, a regulatory subunit of Nox, in hypoxia-induced pulmonary vasoconstriction, vascular remodelling and COPD associated pulmonary hypertension. By comparing end-stage COPD lungs to control lungs, the authors show a significant reduction in $\mathrm{p} 22$ phox expression in the COPD lung that is not restricted to endothelial cells but also involves smooth muscle cells and even the bronchial epithelium. Intriguingly, while the lowest p22phox expression was found in patients with a relatively preserved diffusing capacity of the lung for carbon monoxide (DLCO), higher p22phox expression was associated with a better oxygenation index, a lower DLCO and the presence of pulmonary hypertension. As such, distinct phenotypes were identifiable in this cohort of patients with end-stage, pre-transplant COPD. On one end of the spectrum, patients had dysfunctional HPV and poor oxygenation likely due to ventilation/perfusion mismatch, but preserved pulmonary haemodynamics. On the other end of the spectrum, patients were found with preserved HPV, which allowed better ventilation/perfusion matching but came at the cost of the development of pulmonary hypertension. The investigators followed up on these observations using in vitro experiments and chronic hypoxic exposure of p22phox knock out mice to confirm prior reports on the importance of Nox in HPV (particularly phase II, or sustained HPV) and chronic hypoxic pulmonary hypertension [14-17]. In p22phox knock-out mice, HPV was significantly impaired and in the chronic hypoxic setting, lack of p22phox was associated with decreased pulmonary vascular remodelling and improved right ventricular function.

The paper is important for a number of reasons. By proving a crucial role for p22phox in HPV and vascular remodelling, the paper increases our current understanding of the effects of hypoxia on pulmonary vascular physiology and biology. From a clinical perspective the paper is important for other reasons, however. Its findings illustrate the fact that the previously mentioned poor correlation between arterial oxygen tension and pulmonary artery pressure does not refute a potential causative role of hypoxia in COPD associated pulmonary hypertension. Ventilation perfusion matching is the important intermediary factor that needs to be taken into consideration. As we tell our students, low alveolar oxygen levels only result in low arterial oxygen levels when HPV is insufficient to maintain ventilation perfusion matching. In other words, in some COPD patients arterial oxygen levels may be preserved through a mechanism of HPV at the expense of the development of pulmonary hypertension. The clinical implication of this finding is that the use of vasodilators in COPD will likely come at a price of worsening oxygenation. In fact, most clinical studies on the use of vasodilators in COPD have already shown that pulmonary vascular resistance can be lowered in the condition, but with very little benefit to the patient [18-20]. Even if some pulmonary hypertension drugs ultimately show benefit in COPD, it is probably not because they lower pulmonary artery pressure but rather because they improve maintenance of the pulmonary endothelium [21]. Unfortunately, the double-edged sword of HPV (improving oxygenation while at the same time raising pulmonary pressures) implicates that any intervention to alter $\mathrm{p} 22 \mathrm{phox}$ levels in COPD is unlikely to benefit COPD patients.

Although the paper does not explain why p22phox levels are low in some patients and preserved in others, the observations confirm the much-discussed heterogeneity within COPD patient cohorts, even when all are on a waiting list for lung transplantation. This fact could also point to a potential weakness of the study, however. While the authors suggest causality through their observed correlations between p22phox levels and pulmonary artery pressures and oxygenation, it is entirely possible that the correlations are coincidental because some COPD patients are transplanted predominantly because of poor oxygen levels and others because they developed pulmonary hypertension. Proof is currently lacking that a loss of p22phox leads to poor oxygenation in COPD patients because of impaired HPV and ventilation perfusion mismatch. Alternatively, functional loss of Nox may have also directly promoted the development of emphysema in response to cigarette smoke exposure [22].

While the study of hypoxic responses in the pulmonary vasculature may have seemed obsolete to some ("been there, done that..."), NAGAraj et al. [13] show that there is still a lot to investigate and a lot to be learned. Through a combination of meticulous observations in patient material and detailed physiological and molecular studies in an appropriate animal model, the authors have shown that hypoxic pulmonary vasoconstriction is real and really important in a devastating chronic pulmonary disease. May we continue to look forward to find new ways to fight severe COPD, but at the same time, may we look back once in a while, too.

\section{References}

1 Von Euler US, Liljestrand G. Observations on the pulmonary arterial blood pressure in the cat. Acta Physiol Scand 1946; 12: 301-320 
2 Wang L, Yin J, Nickles HT, et al. Hypoxic pulmonary vasoconstriction requires connexin 40-mediated endothelial signal conduction. J Clin Invest 2012; 122: 4218-4230.

3 Sommer N, Dietrich A, Schermuly RT, et al. Regulation of hypoxic pulmonary vasoconstriction: basic mechanisms. Eur Respir J 2008; 32: 1639-1651.

4 Sylvester JT, Shimoda LA, Aaronson PI, et al. Hypoxic pulmonary vasoconstriction. Physiol Rev 2012; 92: $367-520$.

5 Weir EK, Lopez-Barneo J, Buckler KJ, et al. Acute oxygen-sensing mechanisms. N Engl J Med 2005; 353: 2042-2055.

6 Andersen $\mathrm{KH}$, Iversen $\mathrm{M}$, Kjaergaard J, et al. Prevalence, predictors, and survival in pulmonary hypertension related to end-stage chronic obstructive pulmonary disease. J Heart Lung Transplant 2012; 31: 373-380.

7 Carlsen J, Hasseriis Andersen K, Boesgaard S, et al. Pulmonary arterial lesions in explanted lungs after transplantation correlate with severity of pulmonary hypertension in chronic obstructive pulmonary disease. J Heart Lung Transplant 2013; 32: 347-354.

8 Peinado VI, Pizarro S, Barbera JA. Pulmonary vascular involvement in COPD. Chest 2008; 134: 808-814.

9 Peinado VI, Barbera JA, Ramirez J, et al. Endothelial dysfunction in pulmonary arteries of patients with mild COPD. Am J Physiol 1998; 274: L908-L913.

10 Penaloza D, Arias-Stella J. The heart and pulmonary circulation at high altitudes: healthy highlanders and chronic mountain sickness. Circulation 2007; 115: 1132-1146.

11 Rol N, Happé C, Beliën JAM, et al. Vascular remodelling in the pulmonary circulation after major lung resection. Eur Respir J 2017; 50: 1601651.

12 Blanco I, Piccari L, Barbera JA. Pulmonary vasculature in COPD: The silent component. Respirology 2016; 21: 984-994.

13 Nagaraj C, Tabeling C, Nagy BM, et al. Hypoxic vascular response and ventilation/perfusion matching in end-stage COPD may depend on p22phox. Eur Respir J 2017; 50: 1601651.

14 Sommer N, Strielkov I, Pak O, et al. Oxygen sensing and signal transduction in hypoxic pulmonary vasoconstriction. Eur Respir J 2016; 47: 288-303.

15 Brandes RP, Weissmann N, Schroder K. Nox family NADPH oxidases: Molecular mechanisms of activation. Free Radic Biol Med 2014; 76: 208-226.

16 Mittal M, Roth M, Konig P, et al. Hypoxia-dependent regulation of nonphagocytic NADPH oxidase subunit NOX4 in the pulmonary vasculature. Circ Res 2007; 101: 258-267.

17 Ambasta RK, Kumar P, Griendling KK, et al. Direct interaction of the novel Nox proteins with p22phox is required for the formation of a functionally active NADPH oxidase. J Biol Chem 2004; 279: 45935-45941.

18 Blanco I, Santos S, Gea J, et al. Sildenafil to improve respiratory rehabilitation outcomes in COPD: a controlled trial. Eur Respir J 2013; 42: 982-992.

19 Rietema H, Holverda S, Bogaard HJ, et al. Sildenafil treatment in COPD does not affect stroke volume or exercise capacity. Eur Respir J 2008; 31: 759-764.

20 Holverda S, Rietema H, Bogaard HJ, et al. Acute effects of sildenafil on exercise pulmonary hemodynamics and capacity in patients with COPD. Pulm Pharmacol Ther 2008; 21: 558-564.

21 Dominguez-Fandos D, Valdes C, Ferrer E, et al. Sildenafil in a cigarette smoke-induced model of COPD in the guinea-pig. Eur Respir J 2015; 46: 346-354.

22 Yao H, Edirisinghe I, Yang SR, et al. Genetic ablation of NADPH oxidase enhances susceptibility to cigarette smoke-induced lung inflammation and emphysema in mice. Am J Pathol 2008; 172: 1222-1237. 